\title{
Study of Free-Radical Processes during Rotenone Modeling of Parkinson Disease
}

\author{
Narine A. Ghazaryan, Lusine A. Ghulikyan, Vergine A. Chavushyan, Naira M. Ayvazyan \\ L.A. Orbeli Institute of Physiology NAS RA, Laboratory of Toxinology and Molecular Systematics, Yerevan, \\ Armenia \\ Email: naringhazaryan@gmail.com
}

Received 11 November 2015; accepted 30 January 2016; published 2 February 2016

Copyright (C) 2016 by authors and Scientific Research Publishing Inc.

This work is licensed under the Creative Commons Attribution International License (CC BY).

http://creativecommons.org/licenses/by/4.0/

(c) (i) Open Access

\section{Abstract}

The study has shown free radical processes during modeling of Parkinson Disease (PD) with rotenone. We isolated striatum, brainstem, neocortex, cerebellum, spinal cord, thymus, heart, and liver of rats after rotenone injection in the right striatum. The samples were taken on the 5 th, 10 th and 15th days after the injection. According to chemiluminescence data, the injection of rotenone initiates the disturbance of intensity of free radical processes in striatum at 5 th day in a bilateral mode. After this until the 10th day these changes had restoring character, but after 15 days according to chemiluminescence and thio-barbituric acid test disturbance of lipid peroxide oxidation processes occurred. While superoxide dismutase activity has been changed significantly in all studied tissues, especially in the striatum and neocortex. It should be noted that during rotenone model there are no observed clinical symptoms in rats during 1 to 20 days, and the symptoms of the disease are observed approximately 28 days after the injection. This research could help diagnose PD in the early stage of its onset.

\section{Keywords}

Parkinson's Disease, Rotenone, Chemiluminescence, Thio-Barbituric Acid Test, Superoxide Dismutase Activity

\section{Introduction}

Parkinson's disease (PD) is a progressive neurodegenerative disorder characterized by relatively selective nigrostriatal dopaminergic degeneration and the development of fibrillar cytoplasmicinclusions containing $\alpha$ synuclein and ubiquitin [1] [2]. The etiology of PD is not completely understood, but it is believed to involve an interaction between genetic and environmental factors [3]. 
With the misdiagnosis rate of about 24\% [4] [5] and appearance of symptoms at (>80\%) depletion in striatal dopamine levels [6] [7] it becomes difficult to diagnose PD at an early stage in humans. Whereas, animal models allow us to study the pathology of $\mathrm{PD}$, tracking the physical and behavioral changes during the entire disease course. Amongst the available animal models (e.g. MPTP, 6-OHDA, Reserpine, Paraquatetc), the rotenone (Figure 1) model depicts the classical features of PD [8]-[11]. Moreover, due to its use as an organic pesticide, it has stimulated significant interest in this model of PD [12]-[14].

The investigations of processes of free-radical lipid peroxidation in different parts of brain, liver, heart after 5 , 10, 15 days injection of rotenone let us understand what changes of lipid content are taking place in organism in real-time mode. Free-radical lipid oxidation is a persistent process in intact membranes. The intensity of this process is formed by heterogeneity of lipid content of biomembranes (namely by unsaturation of fatty acids) on one hand and by work of antioxidant system of organisms (fermentative and not fermentative), which regulates this process, on the other hand. During normal functioning of cell, both these components are in dynamic equilibrium, but disturbance of this balance leads to pathological changes in the membrane. The intensity of ChL is a qualitative index of free radical's presence in the system, and different methods of enhanced ChL let us give quantitative characteristics of lipid peroxidation. Most objective results are received during the comparative study of ChL-analysis results and data of biochemical test for determination of malonicdialdehyde (the last product of lipid peroxidation in animal tissues). As mentioned above, the changes of lipid peroxidation without fail lead to the functioning change of antioxidant protection system [15] [16].

So the aim of this research is to study the changes of free radical oxidation processes depending on time in rat tissues (different parts of brain, liver, and heart) via rotenone model.

\section{Materials and Methods}

\subsection{Rotenone Administration}

Under nembutal anesthesia (40 mg/kg) the animals were positioned in a stereotaxic frame, and a midline sagittal incision was made in the scalp. Holes were drilled in the skull over the right striatum using the following coordinates: $1.7 \mathrm{~mm}$ anterior to bregma; $2 \mathrm{~mm}$ lateral to the sagittal suture according to the stereotaxic atlas of Paxinos and Watson [17]. All injections were made using a 10- $\mu$ l Hamilton syringe equipped with a 26S-gauge needle. The needle of the micro syringe was placed $4 \mathrm{~mm}$ beneath the surface of the brain. Animals were injected with rotenone solution (12 $\mu$ g rotenone in $0.5 \mu \mathrm{l}$ DMSO) at a rate of $0.1 \mu \mathrm{l} / \mathrm{min}$ by pump. All procedures were done according to our institution's animal care rules and the IACUC's ethical guidelines for Decapitation of Unanesthetized Mice and Rats (http://www.utsouthwestern.edu/utsw/cda/dept238828/files/469088.html).

\subsection{Tissue Processing}

Non-purebred white rats were decapitated. Then the different parts of brain, liver, heart were homogenized for 5 min by homogenizator of Potter-Elvehejm in Tris-HCl buffer (pH 7.4) with a final concentration of $20 \mathrm{mg} / \mathrm{ml}$.

\subsection{Chemiluminescence Analysis}

Reactive oxygen species (ROS) levels were measured by a ChL analysing system: intensities of tissue homoge-<smiles>C=C(C)[C@H]1Cc2c(ccc3c2O[C@H]2COc4cc(OC)c(OC)cc4[C@@H]2C3=O)O1</smiles>

Figure 1. Structure of rotenone. 
nates and lipid solutions were measured on a quantometric device equipped with FEU-140 (Russia) photomultiplier with a diapason of spectral sensitivity by $300-800 \mathrm{~nm}$. The system contains a photon detector, ChL counter, a water circulator and a 32 bit IBM personal system. A cooler circulator is connected to the FEU-140 photon detector to keep the temperature at $50^{\circ} \mathrm{C}$. This $\mathrm{ChL}$ analyzing system is extremely sensitive, capable of detecting as little as $10-15 \mathrm{~W}$ of radiant energy. ChL intensity was measured in an absolutely dark chamber in impulse/sec mode [18]. The graphical and statistical analysis of data was done by LabView program (National Instruments, USA) [19]. All experiments were performed also by Junior LB 9509 portable tube luminometer (BERTHOLD Technologies, Germany).

\subsection{Lipid Peroxidation}

Lipid peroxides are unstable and decomposed to a complex series of compounds. The most abundant compound is malonicdialdehyde (MDA). The MDA level of tissues was determined by spectrophotometric measurement [20], using the TBA-test, based on the reaction of a chromogenic reagent, thio-barbituric acid (TBA) with MDA at $100^{\circ} \mathrm{C}$ and two molecules of MDA reacting with one molecule of TBA to yield a stable threemethin complex dye. MDA concentration was measured at $532 \mathrm{~nm}$.

\subsection{SOD Activity}

For the determination of superoxide dismutase (SOD) activity we used a method based on the ability of the enzyme to brake the reaction of autooxidation of adrenaline in $\mathrm{pH}=10.2$. Adrenochrom concentration was measured at $480 \mathrm{~nm}$. The amount of the proteins was determined with Lowry's method [21].

\subsection{Statistical Analysis}

For quantitative analysis of chemiluminescence intensity a Student's test was used to compare differences at each time point, considering value of probability $\mathrm{P}<0.05$ as significant. All data were presented as mean \pm $\operatorname{SEM}(\mathrm{n}=$ number of experiments).

\section{Results}

\subsection{Chemiluminescence Analysis}

At the beginning of the experiment we studied spontaneous $\mathrm{ChL}$ of different parts of the brain after 5, 10, 15 days of rotenone injection in the right striatum. Due to this, we can discourse about the free radical oxidation processes of the studied tissues. According to our results (Figure 2), the neocortex has the highest ChL from different parts of brain, which is clear, because the gray matter of the cerebral cortex is the richest with lipids,

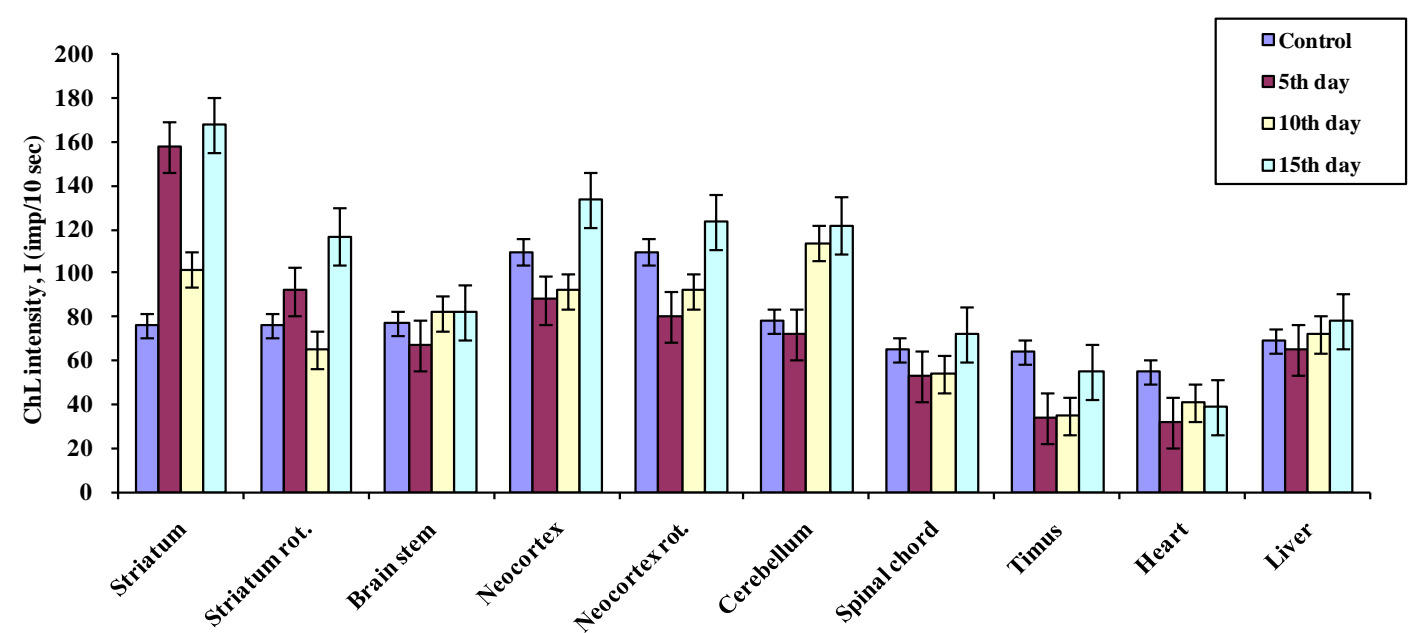

Figure 2. The free radical activity in the rat's brain and other tissues after 5, 10, 15 days of rotenone injection in the right striatum $\left(6 \times 10^{-3} \mu \mathrm{g} / \mu \mathrm{l}\right)$. 
which consist of polyunsaturated acids. The $\mathrm{ChL}$ of these polyunsaturated acids plays a leading role during the delivery of chemical ChL quantum. According to our results, 5 days after the insertion of rotenone, the intensity of free radical processes is very high in the left striatum. In the right striatum the level of chemical ChL is high too but not so significant. In the case of other studied tissues the activity of free radicals is suppressed.

This tendency is observed not only in the tissues of the brain, but also in the thymus, heart liver and in the lumbar segment.

10 days after the injection of rotenone the activity of free radical processes is lower which starve to manage the first (control) level. After this, on the 15th day the intensity of these processes grows in all the studied tissues except the heart. The brain stem (truncus) and liver change the least (during 15 days).

\subsection{Lipid Peroxidation}

In order to observe the unique time correlation between rotenone intoxication we have studied the concentration of MDA, which gives information about the changes during lipid peroxidation concerning the contravention of free radical processes. According to Figure 3 as opposed to data of $\mathrm{ChL}$ analysis, lipid peroxidation processes are the most active in the right striatum and a little bit low in the neocortex. In the other tissues the intensity of these processes is 1.5 - 2 times lower. The level of MDA is very low in the cardiac muscle. 5 days after the rotenone injection in all the tissues, except the cerebellum, the intensity of foregoing processes is much lower.

After 10 days there are no differences concerning the peroxide oxidation processes or there is a decrease in concentration. The opposite results are observed only in the case of the cerebellum and liver. After 15 days the lipid peroxide oxidation processes are mostly suppressed, although in the striatum there is a tendency of level increase.

\subsection{SOD Activity}

In the intact organisms the study of lipid peroxide oxidation logically leads to the necessity of studying the activity of antioxidant enzyme system components. This system leads to the balancing of damage effect, which is made by lipid peroxide oxidation processes in the organisms with normal functionality. For this reason, in the next step of our study we define the activity of SOD in the rat's tissues 5, 10, 15 days after the injection of rotenone, that's parallel to the development of PD model.

According to the ability of the enzyme to brake the reaction of adrenaline autooxidation (Figure 4), (in the case of light, and high $\mathrm{pH}$ ) on the 5th day of rotenone injection the activity of enzyme is significantly changed only in the left striatum and in the neocortex, moreover if in striatum the activity of SOD strictly grows, in the neocortex (where the high level of lipid peroxidation causes a very high activity of SOD in normal conditions) a drastic decrease of this criterion is observed. A significant growth of SOD activity is observed in the studied part of the spinal cord. After 10 days of insertion the opposite data were observed, that's in the striatum the activity of SOD falls, and in the neocortex the activity of SOD grows. On the 10th day the activity of SOD grows very

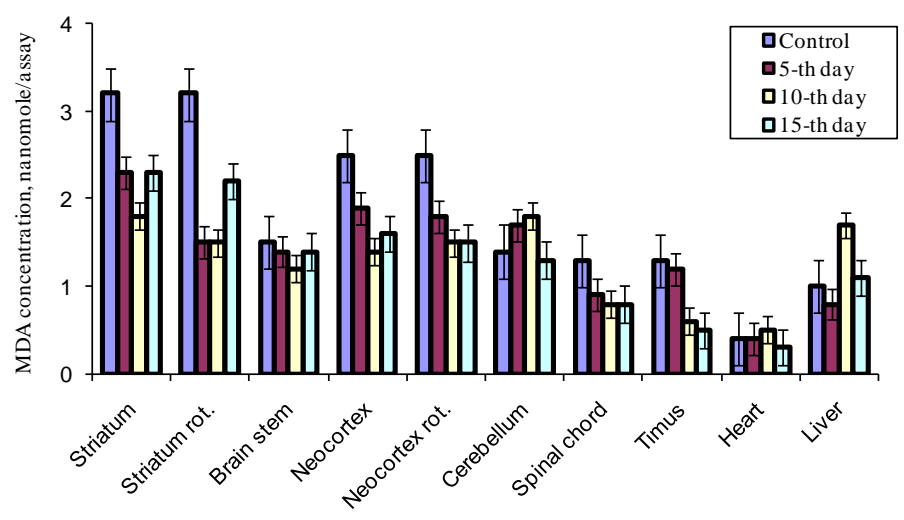

Figure 3. The activity of lipid peroxide oxidation processes in the rat's brain and other tissues after $5,10,15$ days of rotenone injection in the right striatum $\left(6 \times 10^{-3} \mu \mathrm{g} / \mu \mathrm{l}\right)$. 
strictly in the liver tissues. On the 15th day significant changes were observed mostly in the neocortex and liver tissues, where the activity of enzyme is strictly suppressed. On the 15th day the activity of SOD is comparatively a little bit higher in the thymus and in the cardiac muscle (Table 1).

As shown in the figure (Figure 5) after the injection of the rotenone in the right striatum changes appear on the left striatum. There are no differences concerning the peroxide oxidation processes in the left and right striatum during the 15 days, whereas both SOD activity and ChL change dramatically. 5 days after the rotenone injection the intensity of free radical processes is very high in the left striatum, 10 days after the injection of rotenone the activity of free radical processes is lower but on the 15th day the intensity of these processes grows.

SOD activity changes again and in the left striatum it is high but after 10 days of the injection of the rotenone the activity of SOD falls but again grows on the 15th day. It was interesting to follow the changes which took place in the neocortex after rotenone injection. In this case, both SOD activity, MDA concentration and ChL intensity change in the same manner in the right and left neocortex during the 15 days. In both cases (right and left neocortex) the SOD activity decreases drastically on the 5th day, on the 10th day the activity of SOD grows but again on the 15th day the activity of the enzyme is strictly suppressed.

\section{Conclusions}

The analysis of the above cited data allows drawing some conclusions about the development rotenone model of rats concerning the transformation in the brain. It can be assumed, that in the different parts of the brain free

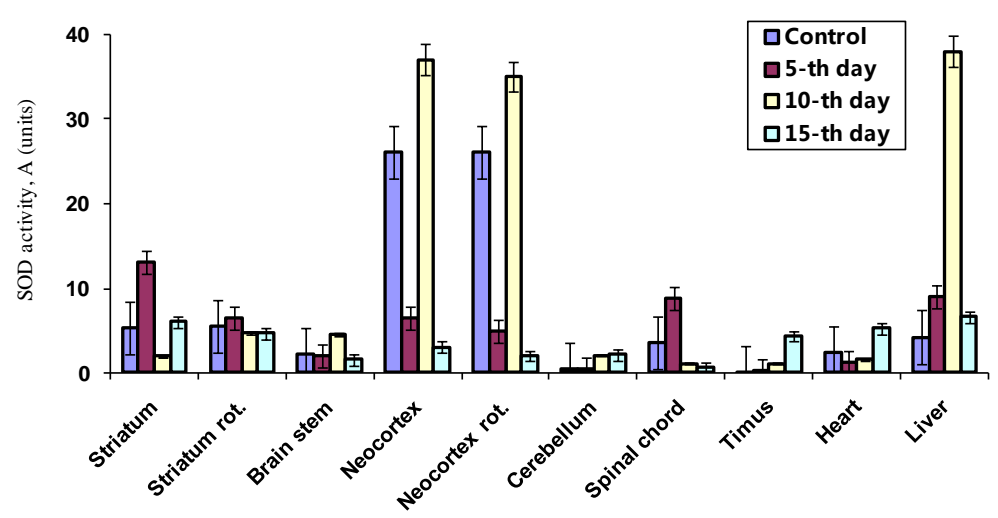

Figure 4. The activity of SOD in the rat's brain and other tissues after 5, 10, 15 days of rotenone injection in the right striatum $\left(6 \times 10^{-3} \mu \mathrm{g} / \mu \mathrm{l}\right)$.

Table 1. The activity of SOD (according the amount of protein in the sample) in the rat's brain and other tissues after 5 , 10 , 15 days of rotenone injection.

\begin{tabular}{|c|c|c|c|c|c|}
\hline \multirow{2}{*}{ Sample } & \multirow{2}{*}{$\begin{array}{l}\text { The amount of } \\
\text { protein in the } \\
\text { sample }(\mu \mathrm{g})\end{array}$} & \multicolumn{4}{|c|}{ 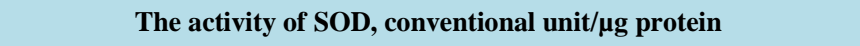 } \\
\hline & & Control & 5th day & 10th day & 15th day \\
\hline Striatum & 68 & 33 & 313 & 25 & 391 \\
\hline Striatum rot. & 51 & 33 & 425 & 71 & 63 \\
\hline Brain stem & 40 & 176 & 17 & 101 & 63 \\
\hline Neocortex & 41 & 718 & 117 & 416 & 234 \\
\hline Neocortex rot. & 39 & 718 & 50 & 769 & 60 \\
\hline Cerebellum & 42 & 18 & 45 & 41 & 55 \\
\hline Spinal chord & 50 & 85 & 197 & 19 & 10 \\
\hline Timus & 45 & 9 & 12 & 26 & 150 \\
\hline Heart & 50 & 86 & 40 & 29 & 148 \\
\hline Liver & 49 & 53 & 527 & 521 & 265 \\
\hline
\end{tabular}




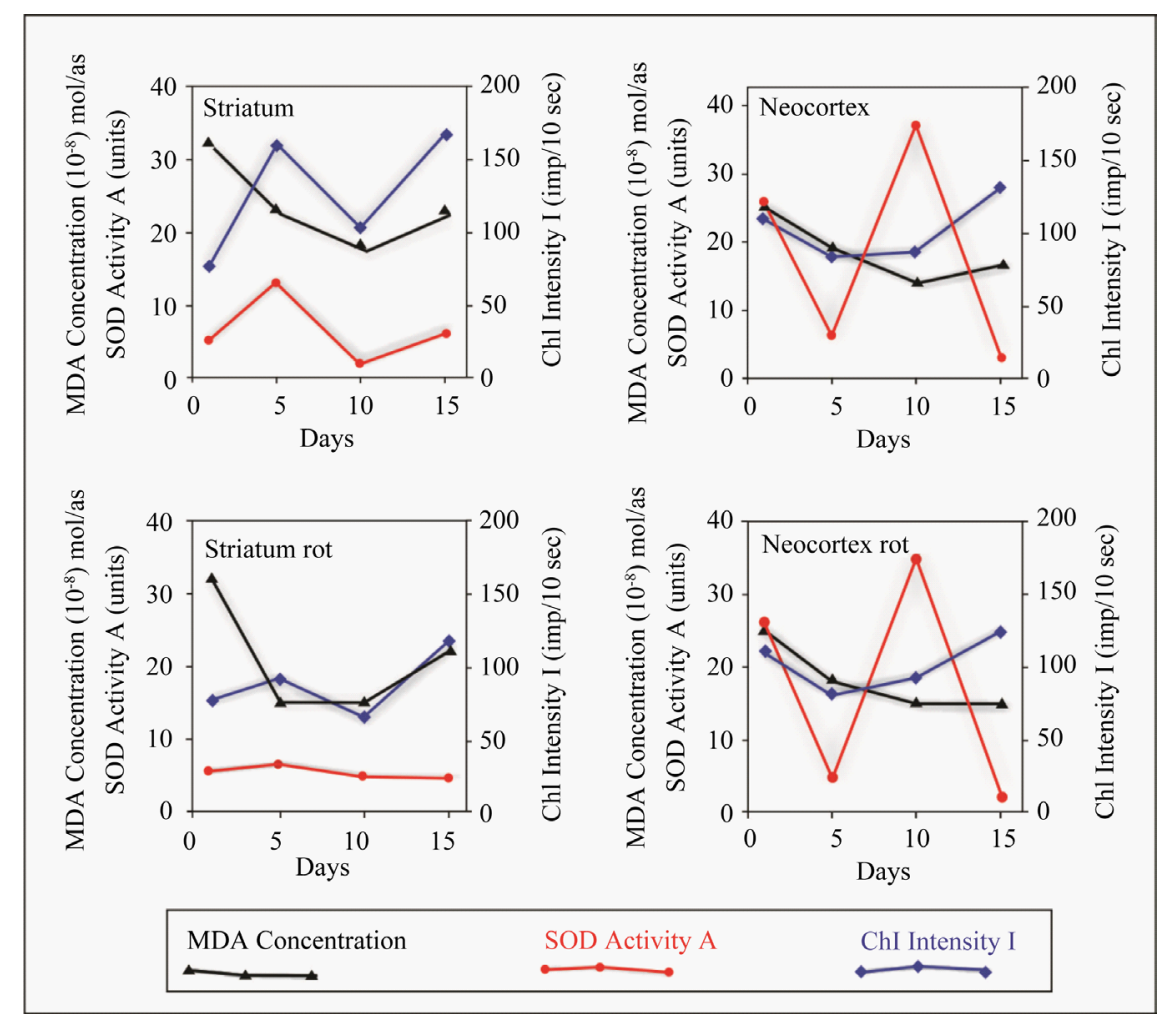

Figure 5. The free radical activity, lipid peroxide oxidation processes and SOD activity in the striatum and neocortex after 5, 10, 15 days of rotenone injection in the right striatum $\left(6 \times 10^{-3}\right.$ $\mu \mathrm{g} / \mu \mathrm{l})$. The concentration of MDA was expressed in the unit mol/assay (mol/as).

radical processes caused by rotenone are quite noticeable on the 5th day, after which temporary regulation occurs, and on the 10th day the restoration of the previous state is observed. But after 15 days, the violations become noticeable again. It should be noted that during this model there are no observed clinical symptoms in rats during 1 to 20 days, and the symptoms of the disease are observed approximately 28 days after the injection and this research could help diagnose PD in the early stage of its onset.

Our results show some differences between the data of the TBA-test and ChL-analysis, which is limited, as we suggest, by methodical specification of the TBA-test, which depends on the participation in the reaction of MDA formation only by di- and polyunsaturated fatty acids, but not monounsaturated ones. Nevertheless, in the course of $\mathrm{ChL}$ analysis the products of monounsaturated fatty acids-hydroperoxides-influence the level of ChL intensity. It is interesting to note, that the acquired data concerning SOD activity corresponded with the studies of American and Indian scientists, who studied SOD activity based on the qualitative reaction of SOD with pyrogallol.

So, it was very interesting to study the ongoing pathologic processes during the latent phase, which according to literature are based on changes of amount of free radical processes [22] [23]. These neurodegenerative processes lead to the disturbance of the respiratory chain in the mitochondria of the brain [24]-[27]. In our future work it will be very interesting to study the activity changes of free radicals in the sub molecular level in the brain parts (for example in the mitochondria and in the synapses and so on).

\section{Acknowledgements}

This work was supported by the Grant International Society for Neurochemistry (ISN). We thank Dr. V. Knaryan for providing rotenone.

\section{References}

[1] Cannon, J. and Greenamyre, J. (2010) Neurotoxic in Vivo Models of Parkinson’s Disease Recent Advances. Progress 
in Brain Research, 184, 17-33. http://dx.doi.org/10.1016/S0079-6123(10)84002-6

[2] Spillantini, M.G., Schmidt, M.L., Lee, V.M., Trojanowski, J.Q., Jakes, R. and Goedert, M. (1997) Alpha-Synuclein in Lewy Bodies. Nature, 388, 839-840. http://dx.doi.org/10.1038/42166

[3] Sherer, T.B., Betarbet, R. and Greenamyre, J.T. (2002) Environment, Mitochondria, and Parkinson's Disease. Neuroscientist, 8, 192-197.

[4] Lang, A.E. and Lozano, A.M. (1998) Parkinson’s Disease. First of Two Parts. New England Journal of Medicine, 339, 1044-1053. http://dx.doi.org/10.1056/NEJM199810083391506

[5] Vernon, G., Carty, A., Salemno, C., Siskind, M. and Thomas, C. (2014) Understanding Parkinson Disease: An Evolving Case Study. Nurse Practitioner, 39, 1-10. http://dx.doi.org/10.1097/01.NPR.0000453646.44157.83

[6] Bezard, E., Dovero, S., Prunier, C., Ravenscroft, P., Chalon, S., Guilloteau, D., Crossman, A.R., Bioulac, B., Brotchie, J.M. and Gross, C.E. (2001) Relationship between the Appearance of Symptoms and the Level of Nigrostriatal Degeneration in a Progressive 1-Methyl-4-Phenyl-1,2,3,6-Tetrahydropyridine-Lesioned Macaque Model of Parkinson's Disease. Journal of Neuroscience, 21, 6853-6861.

[7] Xiong, N., Xiong, J., Jia, M., Liu, L., Zhang, X., Chen, Z., Huang, J., Zhang, Z., Hou, L., Luo, Z., Ghoorah, D., Lin, Z. and Wang, T. (2013) The Role of Autophagy in Parkinson's Disease: Rotenone-Based Modeling. Behavioral and Brain Functions, 9, 1-12. http://dx.doi.org/10.1186/1744-9081-9-13

[8] Bove, J., Prov, D., Perier, C. and Przedborski, S. (2005) Toxin-Induced Models of Parkinsons Disease. Neuro Rx, 3, 484-494. http://dx.doi.org/10.1602/neurorx.2.3.484

[9] Garcia-Garcia, F., Ponce, S., Brown, R. and Cussen, V. (2005) Sleep Distarbances in the Rotenone Animal Model of Parkinson Disease. Brain Research, 2, 160. http://dx.doi.org/10.1016/j.brainres.2005.02.036

[10] Papov, A., Dikalov, S., Shalbuyeva, N., Taylor, G., Sherer, T. and Greenamyre, J.T. (2005) Rotenone Model of Parkinson Disease Multiple Brain Mitochondria Dysfunctions after Short Term Systemic Rotenone Intoxication. Journal of Biological Chemistry, 280, 42026-42035. http://dx.doi.org/10.1074/jbc.M508628200

[11] Sherer, T.B., Richardson, J.R., Testa, C.M., Seo, B.B., Panov, A.V., Yagi, T., Matsuno-Yagi, A., Miller, G.W. and Greenamyre, J.T. (2007) Mechanism of Toxicity of Pesticides Acting at Complex I: Relevance to Environmental Etiologies of Parkinson's Disease. Journal of Neurochemistry, 100, 1469-1479. http://dx.doi.org/10.1111/j.1471-4159.2006.04333.x

[12] Cancela, J., Pastorino, M., Tzallas, A., Tsipouras, M., Rigas, G., Arredondo, M. and Wearability, F.D. (2014) Assessment of a Wearable System for Parkinson's Disease Remote Monitoring Based on a Body Area Network of Sensors. Sensors, 14, 17235-17255. http://dx.doi.org/10.3390/s140917235

[13] Miyasaki, J., Al Hassan, K., Lang, A. and Voon, V. (2007) Punding Prevalence in Parkinson’s Disease. Movement Disorders, 22, 1179-1181. http://dx.doi.org/10.1002/mds.21296

[14] Mulcahy, P., O’Doherty, A., Paucard, A., O’Brien, T., Kirik, D. and Dowd, E. (2012) Development and Characterisation of a Novel Rat Model of Parkinson's Disease Induced by Sequential Intranigral Administration of AAV- $\alpha$-Synuclein and the Pesticide, Rotenone. Neuroscience, 203, 170-179. http://dx.doi.org/10.1016/j.neuroscience.2011.12.011

[15] Dexter, D.T. and Jenner, P. (2013) Parkinson Disease: From Pathology to Molecular Disease Mechanisms. Free Radical Biology \& Medicine, 62, 132-144. http://dx.doi.org/10.1016/j.freeradbiomed.2013.01.018

[16] Przedborski, S. and Ischiropoulos, H. (2005) Reactive Oxygen and Nitrogen Species Weapons of Neuronal Destruction in Models of Parkinson's Disease. Antioxidants \& Redox Signaling, 7, 685-693. http://dx.doi.org/10.1089/ars.2005.7.685

[17] Paxinos, G. and Watson, C. (2005) The Rat Brain in Stereotaxic Coordinates. Compact 6th Edition, Academic Press, New York, 400.

[18] Ayvazian, N.M., Zakharian, A.E. and Karageuzyan, K.G. (2002) Intensity of Lipid’s Free-Radical Oxidation Processes and Superoxid Dismutase's Activity in Nervous Tissue of Vertebrates. Neurochemistry, 4, 278-284.

[19] Zaqaryan, A.E., Elbakyan, V.L. and Ayvazyan, N.M. (2006) The Bases of ChL-Analysis Methodology and LABVIEW Program for Registration and Mathematical Processing of Data. Proceedings of the Conference on Educational, Scientific and Engendering Application in LABVIEW Media and National Instruments Technology, Moscow, 17-18 November 2006, 429-432.

[20] Stalnaja, I.D. and Garishvili, T.G. (1985) Method of Malonic Dialdehide Determination with Thiobarbituroacid. In: Biokhimicheskiemetodiissledovania (Biochemical Methods of Investigations), 66-68. (In Russian)

[21] Lowry, O.H., Resenbrough, N.J., Farr, A.L. and Randall, R.J. (1951) Protein Measurement with the Folin Phenol Reagent. The Journal of Biological Chemistry, 193, 265-275.

[22] Betarbet, R. and Greenamyre, J. (2007) Parkinson's Disease: Animal Models. Handbook of Clinical Neurology, 83, 265-287. http://dx.doi.org/10.1016/S0072-9752(07)83011-9 
[23] Kuranuki, S., Arai, C., Terada, S., Aoyama, T. and Nakamura, T. (2011) Possible Regulatory Factors for Intra-Abdominal Fat Mass in a Rat Model of Parkinson’s Disease. Nutrition, 27, 239-243. http://dx.doi.org/10.1016/j.nut.2009.12.002

[24] Ferro, M., Angelucci, M., Anselmo-Franci, J., Canteras, N. and Da Cunha, C. (2007) Neuroprotective Effect of Ketamine/Xylazine on Two Rat Models of Parkinson's Disease. Brazilian Journal of Medical and Biological Research, 40, 89-96. http://dx.doi.org/10.1590/S0100-879X2007000100012

[25] Mignon, L. and Wolf, W. (2007) Postsynaptic 5-HT1A Receptor Stimulation Increases Motor Activity in the 6-Hydroxydopamine-Lesioned Rat: Implications for Treating Parkinson’s Disease. Psychopharmacology, 192, 49-59. http://dx.doi.org/10.1007/s00213-006-0680-0

[26] Morris, J., Zhang, H., Gupte, A., Bomhoff, G., Stanford, J. and Geiger, P. (2008) Measures of Striatal Insulin Resistance in a 6-Hydroxydopamine Model of Parkinson's Disease. Brain Research, 1240, 185-195. http://dx.doi.org/10.1016/j.brainres.2008.08.089

[27] Sousa, S.C., Macicl, E.N., Vercesi, A.E. and Castilho, R.F. (2003) $\mathrm{Ca}^{2+}$-Induced Oxidative Stress in Brain Mitochondria Treated with the Respiratory Chain Inhibitor Rotenone. FEBS Letters, 543, 179-183. http://dx.doi.org/10.1016/S0014-5793(03)00421-6

\section{Abbreviations}

PD: Parkinson's Disease

ChL: Chemiluminescence

TBA: Thio-Barbituric Acid

SOD: Superoxide Dismutase 